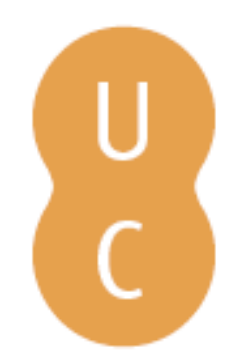

\title{
pombalina
}

\section{Turismo de negócios: Convention \& Visitors Bureau na região centro}

Autor(es): $\quad$ Marques, Jorge Humberto Soares; Santos, Norberto Pinto dos

Publicado por: Imprensa da Universidade de Coimbra

URL

persistente: URI:http://hdl.handle.net/10316.2/30786

DOI: $\quad$ DOI:http://dx.doi.org/10.14195/978-989-26-0244-8_25

Accessed : $\quad$ 26-Apr-2023 15:56:02

A navegação consulta e descarregamento dos títulos inseridos nas Bibliotecas Digitais UC Digitalis, UC Pombalina e UC Impactum, pressupõem a aceitação plena e sem reservas dos Termos e Condições de Uso destas Bibliotecas Digitais, disponíveis em https://digitalis.uc.pt/pt-pt/termos.

Conforme exposto nos referidos Termos e Condições de Uso, o descarregamento de títulos de acesso restrito requer uma licença válida de autorização devendo o utilizador aceder ao(s) documento(s) a partir de um endereço de IP da instituição detentora da supramencionada licença.

Ao utilizador é apenas permitido o descarregamento para uso pessoal, pelo que o emprego do(s) título(s) descarregado(s) para outro fim, designadamente comercial, carece de autorização do respetivo autor ou editor da obra.

Na medida em que todas as obras da UC Digitalis se encontram protegidas pelo Código do Direito de Autor e Direitos Conexos e demais legislação aplicável, toda a cópia, parcial ou total, deste documento, nos casos em que é legalmente admitida, deverá conter ou fazer-se acompanhar por este aviso. 


\section{TRUNFOS DE UMA}

\section{EOGRAFIA ACIVA}

\section{DESENVOLVIMENTO LOCAL,}

AMBIENTE,

ORDENAMENTO

E TECNOLOGIA

Norberto Santos

Lúcio Cunha

COORDENAÇÃO 
Jorge Humberto Soares Marques, Norberto Pinto dos Santos

CEGOT - Centro de Estudos em Geografia e Ordenamento do Território

\section{TURISMO DE NEGÓCIOS \\ CONVENTION \& VISITORS BUREAU NA REGIÃO CENTRO}

\section{INTRODUÇÃO}

O turismo de negócios representa um peso significativo na economia local e regional e corresponde a um segmento turístico com grande potencial de desenvolvimento na Região Centro. Poderá, também, ser enquadrado numa perspectiva dinamizadora do turismo de lazer e de contributo para atenuar a sazonalidade do turismo na Região.

De modo a desenvolver o turismo de negócios, têm surgido em Portugal organizaçóes especializadas denominadas Convention \& Visitors Bureaux (CVB). Estas organizações, sem fins lucrativos, promovem o destino turístico através da divulgação dos espaços onde é possível desenvolver diferentes tipos de eventos e os diferentes serviços e estruturas complementares.

Pretende-se apresentar metodologias e identificar competências organizativas e características territoriais que permitam dar expressão ao turismo de negócios identificando fragilidades e potencialidades como forma de criar um ambiente propício ao desenvolvimento, na Região Centro, deste produto turístico associado ao território.

\section{DEFINIÇÓES E CONCEITOS}

Apesar de contar já com uma longa história, o turismo é um fenómeno que pode ser encarado através de várias perspectivas e pode englobar actividades, motivaçóes ou necessidades sociais nos domínios do lazer, da cultura, da actividade profissional, do conhecimento de outras culturas e áreas geográficas, do desporto, etc.

A primeira definição de turismo data de 1911 quando economista austríaco Hermann von Schullern zu Schattenhofen o definiu como "o conceito que compreende todos os processos, especialmente os económicos, que se manifestam na chegada, permanência e saída do turista de um determinado município, país ou regiāo" (Barretto, 1997). Mais tarde, em 1929, Schwink definiu o turismo como "o movimento de pessoas que abandonam temporariamente o local de residência permanente por motivos relacionados com o espírito, corpo ou profissão" (Fuster, 1974). Poderá considerar-se a definição de Schwink como uma primeira associação das motivaçóes pessoais ao fenómeno do turismo e, mais concretamente, as motivações relacionadas com a profissão como impulso para viajar e fazer turismo. $\mathrm{O}$ conceito de profissão foi mais tarde colocado em causa quando Krapf e Hunziker (1942) 
afirmaram que o turismo poderia ser encarado como conjunto de "fenómenos e relaçôes originados pela deslocação e permanência de pessoas para fora do seu local de residência, desde que tal deslocaçáo e permanência não sejam utilizadas para o exercício de uma actividade lucrativa principal, permanente ou temporária” (Barretto, 1997). Nesta definição o turismo não englobava as deslocaçóes com o objectivo de desenvolver actividade lucrativa, ou seja, actividades profissionais. Esta perspectiva é hoje bem diferenciada visto que o turismo relacionado com os negócios e actividades profissionais constitui uma importante vertente de segmentaçáo.

A definição actual apresentada pela Organização Mundial do Turismo (1998) refere que o turismo "compreende as actividades realizadas pelas pessoas durante as suas viagens e estadas em locais diferentes da sua residência habitual, por um período de tempo consecutivo e inferior a um ano, com objectivos de lazer, de negócios ou outros”. A actividade profissional ou, por outras palavras, o turismo motivado pelos negócios, é contemplada na definição geral de turismo.

\section{O TURISMO DE NEGÓCIOS}

Ao longo dos tempos novos autores e novos conceitos e definiçóes foram surgindo e o estudo do fenómeno do turismo relacionado com os negócios foi-se desenvolvendo. Um dos vários autores a dedicar-se ao estudo deste tipo de turismo foi Davidson (1994). Para ele, o turismo de negócios refere-se ao turismo originado pelas pessoas que viajam por motivos relacionados com o seu trabalho assumindo essa como uma das formas mais antigas do turismo. Também Andrade (1995) definiu este turismo como o conjunto das actividades (viagens, alojamento, alimentação, lazer, etc.) praticado por quem viaja em negócios referentes a qualquer sector de actividade comercial ou industrial, para conhecer mercados, estabelecer contactos, conhecer novas tecnologias, vender ou comprar bens e serviços. Apesar do turismo de negócios associar, numa primeira análise, um carácter profissional e remuneratório ao turista, este segmento não implica necessariamente que haja uma efectivação de negócio ou uma transacção remunerada. Cunha (1997) refere-o ao considerar o turismo de negócios como qualquer actividade que englobe a participação em congressos, viagens de incentivo e interesses específicos, independentemente da efectivação ou não de um negócio. Podemos considerar, deste modo, que o turismo de negócios consiste na viagem motivada por interesses profissionais e/ou outros que impliquem a participaçáo em reunióes. No âmbito da viagem, só por si referência turística relevante, as propostas de turismo estão presentes e resultam do entendimento do lazer como actividade capaz de permitir descanso, recreio, divertimento, desenvolvimento e formação - na perspectiva da procura -, e desenvolvimento local e sustentabilidade ambiental - na perspectiva da oferta ${ }^{1}$.

Em Portugal este segmento de turismo é caracterizado no Plano Estratégico Nacional do Turismo (PENT) onde se releva a importância do turismo de negócios e a definição de estratégias para o seu desenvolvimento. O PENT apresenta como base para o fenómeno

\footnotetext{
${ }^{1}$ Para além das definiçốes, será importante referir a existência de denominaçôes específicas como o acrónimo MICE (meetings, incentives, conventions and exhibitions) que engloba as actividades relacionadas com reunióes, viagens de incentivo, congressos/convenções e exposições/exibições, substituído pela designação de Meetings Industry (MI) como forma de dar uma maior abrangência e força representativa a este segmento turístico.
} 
do turismo de negócios a realização de viagens (e actividades desenvolvidas) com o motivo principal de assistir ou participar numa reunião que, por sua vez, poderá ter um carácter associativo ou corporativo, como desenvolveremos mais adiante.

A nível internacional, a International Congress and Convention Association (ICCA) é uma organização de referência no estudo das reunióes associativas internacionais (mínimo de 50 participantes e realização periódica) apresentando relatórios anuais que são considerados como uma fonte de informação importante para o estudo do turismo de negócios e que contribuíram de modo significativo para a elaboração do PENT e outros estudos relacionados.

\section{EVOLUÇÃO HISTÓRICA DAS VIAGENS EM NEGÓCIOS}

A mais antiga forma conhecida de pessoas que viajavam em negócios remonta a milhares de anos antes do nascimento de Cristo, no tempo em que a troca dos produtos agrícolas entre comunidades predominava.

Durante o período medieval, o mercado de troca estava solidamente implementado com grandes feiras estruturadas fisicamente nas principais cidades para onde se deslocavam comerciantes de todas as partes. A famosa Rota da Seda impulsionou, para além do desenvolvimento de alojamento e restauração ao longo do trajecto, novas actividades relacionadas com as viagens de negócios que consistiram nos transportes (negociantes de camelos) e os próprios guias (pessoas conhecedoras das características do trajecto).

Outras formas foram surgindo ao longo da história das viagens de negócios, como por exemplo, a divulgação da Religião, a deslocação de soldados mercenários para outros pontos geográficos para se juntarem a batalhas ou para ocuparem novos territórios ocupados e os trabalhadores que migravam temporariamente para outras regióes de modo a trabalharem por um período de tempo (carácter sazonal).

A Revolução Industrial e a colonização originaram um forte desenvolvimento das actividades relacionadas com as viagens em negócios, entre 1750 e 1900 . O desenvolvimento do automóvel na primeira metade do século XX impulsionou as deslocaçóes domésticas com carácter comercial e a partir de cerca de 1950 as actividades relacionadas com as viagens de negócios evoluíram fortemente e originaram o desenvolvimento de estruturas especializadas para acolher grandes encontros de pessoas como centros de convençóes e exposiçóes. Mas foi o desenvolvimento do transporte aéreo (a partir da década de 60, com o surgimento das companhias aéreas de avióes a jacto) e o surgimento de novos serviços direccionados para este segmento (classe executiva) que transformaram profundamente a organizaçáo das viagens associadas ao turismo de negócios. Hoje estas realizaçóes medem-se pela distância aos principais aeroportos.

\section{CONVENTION \& Visitors BUREAU}

O primeiro Convention \& Visitors Bureau (CVB) surgiu em 1896 na cidade de Detroit. $\mathrm{O}$ aparecimento destas estruturas organizativas foi impulsionado pelas grandes transformaçôes trazidas pela Revolução Industrial e consequente evolução do mercado de viagens e reunióes relacionadas com os motivos profissionais. 
Em Portugal, actualmente, existem quatro CVB's, nomeadamente no Porto, Lisboa, Estoril/Sintra e Algarve e espera-se que a elaboração deste estudo relacionado com o turismo de negócios apresente estratégias e vantagens organizativas significativas que funcionem como base ao desenvolvimento deste tipo de estrutura na Região Centro.

A existência de um CVB prende-se com o objectivo de promover os locais onde se inserem como destinos ideais para o turismo relacionado com os negócios. A promoção dos equipamentos específicos necessários à realização de reunióes, bem como a promoção de equipamentos e infra-estruturas complementares e todo o leque de atracçóes turísticas torna-se fundamental para cativar a realizaçáo de todo o tipo de actividades relacionadas com negócios.

Um CVB é, geralmente, constituído e financiado como uma sociedade entre organizaçóes privadas e públicas que estejam ligadas directa ou indirectamente ao sector do turismo. Essa sociedade é criada como uma organização sem fins lucrativos, controlada por um quadro de gestão, de modo a desempenhar um papel de marketing estratégico na promoçáo do destino que representam. Em alguns casos, os CVB's podem ser estruturados como prolongamento da autoridade turística local através da criação de balcóes ou secçóes específicas, noutros casos podem ser uma organização autónoma e integral dentro ou fora da própria autoridade turística local, trabalhando sempre em cooperação e com o grande objectivo de desenvolver o turismo local.

O financiamento dos CVB's poderá provir do sector público (em muitos casos, a única fonte de financiamento), da cotizaçáo dos associados do sector privado (os membros podem ser os espaços para a realizaçáo de eventos, estabelecimentos hoteleiros, operadores de transportes, organizaçóes especialistas na organização de eventos, entre outras), dos patrocínios, das actividades comerciais elaboradas com membros associados e, em alguns casos, através de comissóes cobradas aos espaços que acolhem os variados eventos promovidos pelos CVB's.

Com formas organizativas variadas, estruturas e financiamento diferenciados, têm como objectivo primordial a promoçáo e divulgação do território onde se insere de modo a captar a realizaçáo de todo o tipo de eventos relacionados com o turismo de negócios e para os quais haja a oferta de equipamentos e infra-estruturas adequadas.

Relativamente à estrutura, podemos distinguir dois modelos principais: o modelo britanico e o modelo norte-americano. Os CVB's britânicos são, normalmente, compostos, por equipas de duas ou três pessoas (director geral, executivo de vendas e assistente administrativo com boas capacidades informáticas). No entanto, o número de pessoas pode variar (de uma a 12), dependendo do volume de negócios, actividades, estrutura, entre outros. Quanto ao modelo norte-americano, os CVB's têm outra escala de actuação operativa, devido em parte à maior tradição deste tipo de organizaçóes nos Estados Unidos. O financiamento também sofre alteraçóes. O pagamento de uma taxa pelos hóspedes dos hotéis que reverte para a organização local aumenta o orçamento para a promoção do destino.

\section{IMPACTOS DO TURISMO DE NEGÓCIOS}

Segundo dados do Instituto Nacional de Estatística (INE), em 2007 o principal motivo das viagens de estrangeiros a Portugal relacionou-se com o lazer, recreio e férias (cerca de 72\%) seguido da motivação relacionada com actividades profissionais e negócios (cerca de 13\%). 
$\mathrm{Na}$ Região existem vários espaços com as condiçóes necessárias à realização de eventos profissionais, científicos ou culturais que poderão competir com as restantes regióes de Portugal, dos quais se podem destacar o Centro Cultural e de Congressos de Aveiro com o auditório principal com capacidade para 730 pessoas, o Parque de Exposiçóes de Aveiro com auditório principal com capacidade para 224 e dois pavilhóes com capacidade para 5000 pessoas cada, Expocenter Montebelo Hotel \& Spa em Viseu com um saláo principal com capacidade para 2000 pessoas, o auditório da Universidade de Coimbra com capacidade com capacidade para 470 pessoas, o auditório dos Hospitais da Universidade de Coimbra com capacidade para 500 pessoas e o Centro de Artes e Espectáculos da Figueira da Foz com o grande auditório com capacidade para 832 pessoas.

Relativamente ao alojamento, a Regiáo Centro apresenta uma capacidade de 38.148 camas, o que corresponde a cerca de $14 \%$ da oferta total nacional. Cerca de $40 \%$ da oferta de alojamento da Região distribui-se pelas sub-regióes de Baixo Vouga, Baixo Mondego, Dão Lafôes e Pinhal Interior Norte que, por sua vez, abrangem o triângulo urbano Coimbra Aveiro - Viseu. Ainda referente ao alojamento, tem-se verificado um crescente investimento na qualificação hoteleira e posicionamento estratégico dos empreendimentos turísticos para captar o turismo de negócios através não só remodelação das unidades hoteleiras existentes (de modo a dotarem-se de espaços para reuniôes) mas também através da construção de novas e modernas unidades direccionadas para este importante segmento turístico, como é exemplo o Hotel Vila Galé Coimbra, caracterizado como leisure \& conference hotel.

\section{REUNIÓES ASSOCIATIVAS E REUNIŌES CORPORATIVAS}

De acordo com o Plano Estratégico Nacional (PENT), que engloba no conceito de reuniáo todas as actividades profissionais que o turista de negócios pode desenvolver no destino, o tipo de reunião poderá ter um carácter associativo ou corporativo.

As reunióes associativas são, geralmente, convocadas por organizaçôes nacionais ou internacionais, associaçóes e organismos públicos, e traduzem-se em congressos, assembleias, conferências, encontros, fóruns, simpósios, etc. São compostas por uma maior heterogeneidade de participantes, com uma duração habitual de três a cinco dias, de grande dimensão, com tendência a repetirem-se no tempo, apesar da periodicidade poder ser variável. O tempo de preparação deste tipo de reunióes é longo, com um processo de decisão lento e complexo. Verifica-se maior variedade na escolha dos locais onde se realizam e é atribuída maior importância relativa aos aspectos alheios às instalaçóes das reuniôes, ou seja, as actividades e equipamentos complementares do destino turístico poderão influenciar a escolha.

No caso das reunióes corporativas, são organizadas por corporaçóes ou grupos empresariais, companhias multinacionais e empresas, e traduzem-se em convençóes, jornadas, seminários, apresentaçóes, cursos, workshops, conselhos de administraçáo, etc. Caracterizam-se pela maior homogeneidade de participantes, por uma curta duração, menor dimensão, maior repetição do local onde se realiza e por uma maior importância atribuída à utilizaçáo de equipamentos e serviços específicos. No caso das reunióes corporativas o processo de decisão é mais rápido, o processo de preparação mais curto e, geralmente, a realização deste tipo de reuniōes depende mais directamente da necessidade na sua realização. 


\section{O MERCADO DAS REUNIÓES ASSOCIATIVAS}

Segundo dados da International Congress \& Convention Association (ICCA), em 2007 realizaram-se 3.719 reuniōes associativas internacionais na Europa, num total de 6.681 reunióes no mundo inteiro, o que contabiliza cerca de $55,7 \%$ do mercado total. Considerando que em 2003 a Europa apresentava uma cota de mercado de cerca de 58,5 $\%$, verifica-se que de 2003 até 2007 o valor percentual tem descido. A ICCA prevê uma recuperação do sector devido à entrada dos novos países membros da União Europeia, e estima um crescimento superior ao do turismo em geral (3\%) para os anos subsequentes.

Em 2007 Portugal ocupava o $15^{\circ}$ lugar nos países mundiais com maior número de reunióes (153), com os Estados Unidos da América, Alemanha e Espanha a ocupar os três primeiros lugares com, respectivamente, 467, 430 e 307 reunióes.

No que respeita ao ranking das cidades mundiais, os três primeiros lugares são ocupados por Viena, Berlim e Singapura com, respectivamente, 154, 123 e 120 reunióes. Lisboa ocupava o $6^{\circ}$ lugar com 90 reuniôes à frente de cidades como Madrid (77), Londres (69) e São Paulo (61). A cidade do Porto aparece na posição 56 com 23 reuniôes e Faro na posição 208 com 6 reunióes realizadas no ano de 2007. Com um número médio de 767 participantes por reuniáo, no ano de 2007, registaram-se 2.327 .115 participantes nas reunióes associativas internacionais na Europa, o que corresponde a cerca de 54,9\% do mercado total.

O ranking dos países com o maior número estimado de participantes em reunióes apresenta os Estados Unidos em primeiro lugar (427.556), seguido da Itália e Alemanha com, respectivamente, 349.614 e 305.809 participantes. Portugal ocupa a $21^{\text {a }}$ posição após ter recebido cerca de 71.274 participantes durante o ano de 2007.

Relativamente ao número de participantes por cidade, Viena, Barcelona e Berlim ocupam os três primeiros lugares com cerca de 117.774 , 108.933 e 76.171 participantes, respectivamente. Lisboa ocupa o $13^{\circ}$ lugar com 32.779 participantes.

Os tipos de instalaçôes mais utilizados para a realização de reuniôes associativas, durante o ano de 2004, foram centros de conferências/congressos com uma percentagem de cerca de $44 \%$, hotéis com cerca de $26 \%$ e as Universidades com cerca de $16 \%$.

\section{O MERCADO DAS REUNIỐES CORPORATIVAS}

No que respeita a reunióes corporativas internacionais, verifica-se que não existe informação estatística sistematizada internacionalmente. Ao nível de cada país, constata-se que apenas existem estimativas aproximadas do volume representativo desta actividade, facto que se justifica através das próprias características deste tipo de reuniōes, extremamente difíceis de contabilizar para efeitos estatísticos. Estima-se, portanto, que terão ocorrido cerca de um milhão de reunióes corporativas na Europa e que cada empresa ou companhia organiza, em média, sete reunióes ao ano. A dimensão é variável e poderá ir desde 20 (ou menos) participantes até aos 100 . Cerca de $63 \%$ das reuniôes corporativas têm lugar no próprio país da companhia e cerca de $70 \%$ das reunióes corporativas realizam-se em hotéis urbanos, daí a atenção dada a este segmento pelas unidades de alojamento. 


\section{CONCLUSÃO}

A Região Centro de Portugal apresenta factores diferenciadores relativamente à riqueza e diversidade das atracçóes turísticas, localização geográfica, acessibilidades, segurança e hospitalidade. Algumas das atracções turísticas da Região poderão ser exemplificadas através de produtos que poderão complementar o turismo de negócios. Entre muitas outras atracçóes podemos destacar alguns exemplos como a riqueza gastronómica e vinícola (região gastronómica e vitivinícola da Bairrada, região vitivinícola do Dão), termalismo (termas de São Pedro do Sul e do Luso, entre outras), golfe (futura academia de Cantanhede, Curia Golfe, Montebelo Golfe e Lágrimas Golfe), as numerosas caves da regiáo da Bairrada, património natural e paisagístico das serras da Lousã e Caramulo e dos rios Vouga e Mondego. O vasto património arquitectónico (centro histórico de Viseu, centro histórico de Coimbra e Arte Nova de Aveiro) e diversidade cultural da regiáo complementam o grande leque de oferta turística complementar que será possível oferecer a quem se deslocar à Regiáo.

A localizaçáo geográfica da Região Centro e mais especificamente o triângulo urbano Coimbra - Aveiro - Viseu apresenta uma boa estrutura de acessibilidades rodoviárias que ligam estas cidades entre si e também aos centros urbanos de Porto e Lisboa. A existência de vários aeródromos (Aveiro, Coimbra, Viseu, Figueira da Foz, entre outros) e dos portos marítimos de Aveiro e Figueira da Foz apresentam-se como vantagem competitiva que tenta atenuar a o facto de não existirem aeroportos na Região. Ao nível de estruturas e equipamentos, existem vários espaços com as condiçóes necessárias à realização de eventos profissionais, científicos ou culturais que poderão competir com as restantes regióes de Portugal, dos quais se podem destacar o Centro Cultural e de Congressos de Aveiro, o Expocenter em Viseu, o Centro de Artes e Espectáculos da Figueira da Foz e o Auditório dos Hospitais da Universidade de Coimbra.

Todos estes factores diferenciadores propiciam à Região um grande potencial de desenvolvimento turístico e do produto associado ao turismo de negócios.

Figura 1 - Matriz Estratégica dos Produtos Turísticos, por Região.

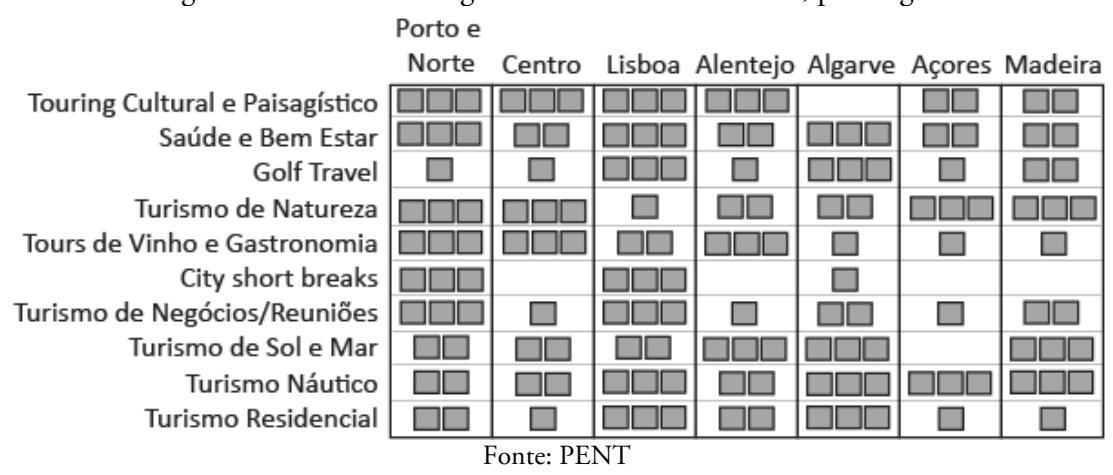

Ao analisar os 10 produtos turísticos definidos pelo Plano Estratégico Nacional do Turismo (Figura 1), os que mais contribuem para o volume global de receitas na Região são o Touring Cultural e Paisagístico, o Turismo de Natureza e Gastronomia e Vinhos. Considerase, no entanto, que o desenvolvimento de outros produtos é de grande importância, nomea- 
damente o turismo de negócios que, apesar de não fazer parte dos produtos prioritários definidos pelo PENT para a Região Centro, poderá representar um contributo significativo para a actividade turística. Considera-se importante promover estratégias de desenvolvimento não só para o turismo de negócios de grandes dimensóes através de grandes eventos corporativos ou associativos, como também para o de menores dimensóes que engloba as deslocaçóes de representantes comerciais de empresas, pequenas reunióes, visitas técnicas, entre outros. Este segmento turístico poderá também ser enquadrado numa perspectiva dinamizadora do turismo de lazer e mais concretamente dos restantes produtos estratégicos definidos pelo PENT, devido às riquezas naturais, culturais e construídas da Região. Quanto maior o leque de atracçóes maior é a diversidade de actividades que podem ser oferecidas aos turistas após a realização do propósito principal da viagem ou visita. Atenuador da sazonalidade do turismo, as actividades existentes, relacionadas com o tempo de lazer, podem levar o turista a prolongar a permanência na região ou mesmo a regressar numa outra altura, acompanhado pelos familiares ou amigos, impulsionado por outras motivaçôes que não as ligadas aos negocios ou actividades profissionais.

\section{REFERÊNCIAS BIBLIOGRÁFICAS}

Barretto, M. 1997, Manual de Iniciação ao Estudo do Turismo, 2 ed., Papirus, São Paulo;

Beech, J., \& Chadwick, S. 2006, The Business of Tourism Management, Prentice Hall, England;

Buhalis, D. \& Costa, C. 2006, Tourism Business Frontiers: Consumers, Products and Industry, Elsevier, Oxford;

Cunha, L. 2006, Economia e Politica do Turismo, Verbo, Lisboa;

Cunha, L. 2003, Introdução ao Turismo, Verbo, Lisboa;

Davidson, R. 1994, Business Travel, Longman, Harlow;

Davidson, R. \& Rogers, T. 2006, Marketing Destinations and Venues for Conferences, Conventions and Business Events, Elsevier, England;

Frochot, I. \& Legohérel, P. 2007, Le Marketing du Tourisme, Dunod, Paris

Fuster, L. 1974, Teoria y Técnica del Turismo, Nacional, Madrid;

Hall, C. M. \& Page, S. 2005, Geography of Tourism and Recreation: Environment, Place and Space, Routledge, London;

Hall, C. M. 2005, Tourism, Rethinking the Social Science of Mobility, Pearson Prentice Hall, Harlow;

ICCA, 2008, The International Association Meetings Market 1998-2007, Amesterdam

Kotler, P., Bowen, J. \& Makens, J. 2003, Marketing for Hospitality and Tourism, Prentice Hall, Upper Saddle River;

MEI, 2006, Plano Nacional de Turismo 2006-2015, Secretaria de Estado do Turismo, Ministério da Economia e Inovação, Lisboa;

Morgan, R. Pritchard, A. \& Pride, R. 2002, Destination Branding: Creating the Unique Destination Proposition, Butterworth-Heinemann, England;

Rice, C. 1993, Consumer Behavior: Behavioural Aspects of Marketing, Butterworth-Heinemann, Oxford;

Rutherford, D. C. 1990, Introduction to the Conventions, Expositions and Meetings Industry, Van Nostrand Reinhold, New York;

Santos, Norberto P. 2005, Lazer, Espaço e Lugares, in: Gomes, Rui (coord), Os Lugares do Lazer, Instituto do Desporto de Portugal, Lisboa;

Santos, Norberto P. 2008, Lazer: Da libertação do tempo à conquista das práticas, Imprensa da Universidade de Coimbra, Coimbra;

Shaw, G. \& Williams, A. 2004, Tourism and Tourism Spaces, Sage, London;

Swarbrooke, J. \& Horner, S. 2001, Business Travel and Tourism, Butterworth-Heinemann, Oxford;

Umbelino, J. 1999, Lazer e Território: Contributo Geográfico para a Análise do Uso do Tempo, Centro de Estudos de Geografia e Planeamento Regional, Série Estudos, nº1, Lisboa;

Urry, John 1995, Consuming Places: The Marketing and Promotion of Towns and Cities 1850-2000, Routledge, London; 
Ward, Stephen. V. 1998, Selling Places, Routledge, London;

Weiermair, W. \& Pérez, S. 2006, Innovation and Product Development in Tourism, Erich Schmidt Verlag, Berlin.

\section{FONTES ELECTRÓNICAS}

http://www.ine.pt, consultada em 03/10/2009

http://www.iccaworld.com/, consultada em 03/10/2009 